$p$-ISSN 1693-9484, $e$-ISSN : 2621-8313

Majalah Ilmiah Bahari Jogja (MIBJ)

Vol. 16 No. 2, Juli 2018 (126-147)

(C) 2018 Akademi Maritim Yogyakarta

BAHARI JoGjA

\title{
POLA SALURAN PEMASARAN IKAN DI DAERAH ISTIMEWA YOGYAKARTA (DIY)
}

\author{
Cahya Purnomo ${ }^{{ }^{*}}$ \\ ${ }^{1}$ Akademi Maritim Yogyakarta, Jl. Magelang KM 4.4, Yogyakarta 55284, Indonesia \\ * Corresponding Author. E-mail: cahyapiyungan@gmail.com. Telp. 0802743861
}

\begin{abstract}
Abstrak
Tujuan penelitian mengetahui pola saluran pemasaran ikan di DIY. Data dikumpulkan dengan purposive sampling, yaitu Tempat Pelelangan Ikan (TPI) Gunung Kidul 2 dan Kulon Progo 1, Nelayan Gunung Kidul 6 dan Kulon Progo 4, pedagang perantara Gunung Kidul 4 dan Kulon Progo 3 orang. Analisisnya mendiskripsikan pola saluran pemasaran dan menghitung fisherman's share. Hasilnya bahwa ikan yang beredar di DIY $60 \%$ berasal dari Pantai Utara Jawa dan $40 \%$ dari DIY, produksi ikan DIY diekspor $40 \%$ terutama jenis ikan yang bernilai tinggi. Pola saluran pemasaran ada 4. Pola 1 adalah nelayan - TPI - konsumen akhir dengan fisherman's share $95 \%$ untuk semua jenis ikan, saluran pemasaran ini paling efektif. Pola 2 adalah nelayan - TPI - pedagang pengumpul - pedagang pengecer - konsumen akhir dengan fisherman's share bervariasi antara $48 \%$ sampai $71 \%$. Pola 3 adalah nelayan - TPI - pedagang pengumpul - rumah makan - konsumen akhir, dengan fisherman's share bervariasi antara $39 \%$ sampai $64 \%$. Pola 4 adalah nelayan - TPI - pedagang pengumpul - industri pengolah konsumen akhir, fisherman's share diketahui hanya sampai pada pedagang pengumpul, bervariasi dari $61 \%$ sampai $85 \%$. Transaksi penjualan pada semua pola selalu melibatkan TPI sebagai mediator antara nelayan dengan pelaku pemasaran berikutnya.
\end{abstract}

Kata kunci: pola saluran pemasaran, fisherman's share

\begin{abstract}
This study aims to analyse fish's marketing channel pattern of Yogyakarta Region. Data gathering by purposive sampling, that comprise 2 fish auctions of Gunung Kidul District and 1 of Kulon Progo District, 6 fishermans of Gunung Kidul District and 4 from Kulon Progo District, 4 intermediary trader of Gunung Kidul District and 3 from Kulon Progo District. Analysis used by describe fish's marketing channel pattern and counts to fisherman's share. The result showed that $60 \%$ of fish circulating in DIY come from the North Coast of Java and 40\% from Yogyakarta Region. Yogyakarta Region fish production is exported 40\%, especially high-value fish. There are 4 patterns of marketing channels. Pattern 1 is fisherman - fish auctions - end consumer by fisherman's share $95 \%$ for all species, this type is most effective channel. Pattern 2 is is fisherman - fish auctions collector traders - retailer trader-end consumer by variety fisherman's share from $48 \%$ so $71 \%$. Pattern 3 is is fisherman - fish auctions - collector traders restaurant - end consumer by variety fisherman's share from $39 \%$ sampai $64 \%$. Pattern 4 is fisherman - fish auctions - processing industry - end consumer, that
\end{abstract}


fisherman's share is known to collector traders only from $61 \%$ to $85 \%$. All fish transaction always through fish auctions as mediator between fisherman and next marketing stakeholder.

Keywords: marketing channel pattern, fisherman's share

\section{PENDAHULUAN}

\section{Latar Belakang Masalah}

Kondisi geografis wilayah pesisir Provinsi Derah Istimewa Yogyakarta (DIY) yang sebagian berupa pesisir memungkinkan sebagai daerah produsen ikan laut (seterusnya disebut ikan) dan masyarakatnya sebagai konsumen. Berikut adalah tabel kondisi geografis wilayah pesisir DIY.

Tabel 1. Wilayah Pesisir Daerah Istimewa Yogyakarta

\begin{tabular}{|l|l|c|c|c|c|}
\hline No & \multicolumn{1}{|c|}{ Keterangan } & $\begin{array}{c}\text { Kab. Kulon } \\
\text { Progo }\end{array}$ & Kab. Bantul & $\begin{array}{c}\text { Kab. Gunung } \\
\text { Kidul }\end{array}$ & DIY \\
\hline 1 & Panjang pantai (KM) & 25 & 17 & 71 & 113 \\
\hline 2 & Luas wilayah daratan (Ha) & 5.702 & 4.242 & 32.277 & 42.225 \\
\hline 3 & Luas perairan (Ha) & 55.560 & 37.780 & 257.790 & 251.130 \\
\hline 4 & $\begin{array}{l}\text { Jumlah kecamatan } \\
\text { pesisir }\end{array}$ & 4 & 3 & 6 & 13 \\
\hline 5 & Jumlah desa pesisir & 41 & 11 & 35 & 87 \\
\hline 6 & $\begin{array}{l}\text { Jumlah penduduk } \\
\text { wilayah pesisir (jiwa) }\end{array}$ & 130.483 & 114.027 & 230.388 & 474.898 \\
\hline 7 & Jumlah pulau & - & - & 28 & 28 \\
\hline
\end{tabular}

Sumber: Hamengkubuwono X, 2015

Usaha penangkapan ikan di DIY dilakukan di perairan pantai sepanjang 113 KM yang berada di tiga kabupaten, yaitu Kabupaten Gunung Kidul, Bantul, dan Kulon Progo. Menurut Kamiso (2002), Laut Selatan Jawa merupakan daerah penangkapan ikan potensial untuk dikembangkan, karena baru dimanfaatkan 50 $\%$ dari potensi lestari.

Dari sisi konsumsi ikan, masyarakat DIY termasuk yang terendah di tingkat nasional, pada tahun 2011 hanya 11,53 kg perkapita pertahun, sementara tingkat nasional mencapai $35 \mathrm{~kg}$ perkapita pertahun (Kedaulatan Rakyat, 4 Februari 2016). Rendahnya konsumsi ikan tersebut salah satu yang disinyalir adalah karena masalah distribusi ikan yang berakibat pada tingkat ketersediaan di pasaran dan tentunya harga yang terjangkau. 
Studi tentang perikanan mayoritas berfokus pada peningkatan produksi dan perbaikan kualitas produksi. Perbaikan produksi tidak diikuti dengan peningkatan akses terhadap pasar untuk mendapatkan harga dan margin keuntungan yang lebih baik. Pemasaran bersama mengalami pasang surut. Maka berdasarkan fenomena tersebut penelitian ini mempunyai kontribusi dan kebaruan.

\section{Perumusan Masalah}

Permasalahannya penelitian ini adalah: (a) Bagaimana pola saluran pemasaran ikan di DIY. (b) Bagaimana model saluran pemasaran ikan di DIY yang efektif. (c) Berapa margin pemasaran / fisherman's share masing-masing pelaku saluran pasar ikan di DIY.

\section{Tujuan Penelitian}

Tujuan penelitian ini adalah: (a) Ingin mengetahui pola saluran pemasaran ikan di DIY. (b) Ingin mengetahui model saluran pemasaran ikan di DIY yang efektif. (c) Ingin menghitung margin pemasaran / fisherman's share masing-masing pelaku saluran pasar ikan di DIY.

\section{KAJIAN LITERATUR}

\section{Sumberdaya Ikan dan Kesejahteraan}

Ikan laut (pisces maris), adalah salah satu sumberdaya laut yang dapat dikonsumsi untuk kesejahteraaan manusia di bumi. Menurut Adisasmita (2006), ikan merupakan salah satu unsur pembangunan maritim. Perikanan merupakan mata pencaharian pokok para nelayan. Penangkapan masih dilakukan dengan dengan cara-cara tradisional karena pengetahuan dan modal sangat terbatas (Mubyarto, 1989).

Bappenas, pada tahun 2013 melansir bahwa berdasarkan data dari Badan Pangan Dunia, pada tahun 2012, Indonesia menempati peringkat ke-2 untuk produksi perikanan tangkap laut. Artinya pembangunan nasional yang berbasis perikanan benar-benar penting dalam meningkatkan kesejahteraan masyarakat.

Studi Oktariza et al (1996), menunjukkan bahwa pemasaran ikan dari Pelabuhan Ratu, Sukabumi Jawa Barat menghasilkan fisherman's share sebesar 
$68,65 \%$ dan pelaku pemasaran lainnya rata-rata 59,96\%. Studi-studi yang lain juga mengindikasikan bahwa fisherman's share angkanya umumnya di atas $50 \%$.

\section{Pentingnya Pemasaran Produk Perikanan}

Sedikit Konsep Pemasaran

Menurut Kotler and Keller (2012), marketing is about identifying and meeting human and social neesds. Kata kuncinya di sini adalah menemukan kebutuhan masyarakat untuk dilayani, yang pada perspektif bisnis tentu dengan keuntungan wajar. Idealnya marketing harus menyediakan produk yang diinginkan konsumen untuk dibeli.

Pengertian pemasaran (marketing) adalah luas sekali, tetapi pada prinsipnya adalah distribusi-penyampaian produk dari produsen ke konsumen. Distribusi (saluran pemasaran) adalah bagian dari marketing mix (Webster Jr;1992, McCarthy and Perreault; 2002). Dalam lingkup agribisnis, distribusi juga berarti tataniaga dan juga berarti pemasaran / marketing (Soekartawi; 1989, Mubyarto; 1989, Hanafie; 2010 ). Masalah pemasaran perikanan adalah terjadinya perbedaan harga / margin pemasaran yang besar antara nelayan dengan konsumen akhir. Semakin tiggi margin pemasaran berarti semakin tidak adil, dan sebaliknya (Soekartawi; 1989, Mubyarto; 1989).

\section{Karakteristik Produk Perikanan}

Perikanan termasuk rumpun produk pertanian. Menurut Soekartawi (1993), secara umum produk perikanan berkarakteristik sebagai berikut:

1. Produk perikanan bersifat musiman, tidak mungkin tersedia sepanjang waktu. tidak dapat distok, begitu dihasilkan harus segera dipasarkan/ dikonsumsi.

2. Produk bersifat segar dan mudah rusak sehingga tidak dapat distok, begitu dihasilkan harus segera dipasarkan/ dikonsumsi.

3. Produk perikanan tidak selalu mudah didistribusikan ke semua tempat. Karakteristik perikanan di Indonesia adalah merupakan konsekwensi dari pegara kepulauan dan topografinya yang bergunung-gunung (Mubyarto,

Majalah Ilmiah Bahari Jogja 129 | http://jurnal.amy.ac.id/index.php/MIBJ/ 
1989). Kondisi ini mengakibatkan pada tataniaganya dalam bentuk saluran pemasaran yang panjang

4. Produk perikanan bersifat lokal. Beberapa produk perikanan hanya dapat dihasilkan dari laut tertentu.

5. Produk perikanan mempunyai guna beragam. Ikan dapat digiling menjadi tepung ikan, minyak ikan, ikan kaleng, ikan asap, pakan ternak dan seterusnya.

6. Perikanan memerlukan ketrampilan khusus yang sulit disediakan, tidak setiap orang dapat melaut untuk menangkap ikan.

Dampak dari karakteristik tersebut adalah aktivitas usaha / pemasaran tidak dapat berlangsung sepanjang waktu (Laporan Kinerja Kementerian Kelautan dan Perikanan Tahun 2014), ketidakseimbangan permintaan dan penawarannya, harga tidak stabil, serta ketidakpastian keuntungan bagi pelaku pasarnya.

\section{Saluran Distribusi Produk Perikanan}

Menurut Kotler and Keller (2012), pengertian lebih luas saluran distribusi adalah rantai pasok (supply chain), yang meliputi saluran dari raw material - produk - pembeli akhir. Dalam lingkup rantai pasok, nelayan - pedagang antara - konsumen akhir merupakan kesatuan terintegrasi. Menurut Watanabe and Schuster (2003), penerapan supply chain management (SCM) dapat meningkatkan efektivitas dan efisiensi distribusi produk perikanan. Sementara menurut Bourlakis and Weightman (2004), penerapan SCM bermanfaat menciptakan produk berkualitas, harga murah dan pasokan sesusai kebutuhan konsumen.

Studi Balitbang Kementerian Pertahanan (2012), melaporkan bahwa SCM produk perikanan di Kabupaten Rote Ndao digambarkan sebagai bertikut:

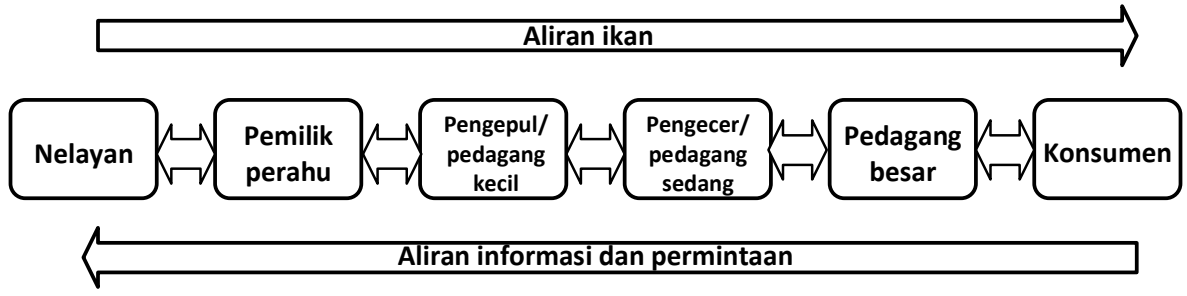

Gambar 1. SCM Produk Perikanan di Kabupaten Rote Ndao

Sumber: Balitbang Kementerian Pertahanan (2012), dengan Penyesuaian

Majalah Ilmiah Bahari Jogja 130 | http://jurnal.amy.ac.id/index.php/MIBJ/ 
Pada gambar di atas nampak bahwa produk perikanan yang dihasilkan oleh nelayan tidak ada yang dipasarkan melalui saluran distribusi langsung nelayankonsumen. Artinya peran pedagang perantara (apakah kecil, sedang atau besar) atau bahkan pemilik perahu menjadi bagian rantai pasok produk perikanan yang terintegrasi.

\section{METODE PENELITIAN}

\section{Pengumpulan Data}

Pengumpulan data dengan purposive sampling (Soekartawai; 1995, Sugiyono; 2014). Sampel nelayan yang dipilih sebanyak 10 orang masing-masing dari nelayan Gunung Kidul 6 orang dan Kulon Progo 4 orang. Pedagang perantara yang dipilih dari Gunung Kidul 4 orang dan dari Kulon Progo 3 orang. Tempat Pelelangan Ikan yang dipilih dari Gunung Kidul 2 TPI dan dari Kulon Progo 1 TPI. Alasan menentukan lokasi di Gunung Kidul dan Kulon Progo karena kedua kabupaten ini masing-masing merupakan penghasil ikan laut terbesar di DIY, di mana Gunung Kidul berkontribusi 79 \% dari seluruh ikan laut DIY. Waktu pengambilan data lapangan adalah bulan Maret sampai Mei 2016, dengan pertimbangan bahwa selama bulan-bulan tersebut bulan paceklik dan ada bulan panen, sehingga diasumsikan produksinya rata-rata

\section{Analisis Data}

1. Analisis Pola Saluran Pemasaran

Analisis pola saluran (distribusi) pemasaran dengan mengidentifikasi pelaku pemasaran ikan di DIY, dari tingkat nelayan, pelaku perantara, sampai konsumen akhir (Hanafiah dan Saefuddin; 2010, Soekartawi; 1989, Soekartawi; 1993). Tahap terakhir menggambarkan pola saluran pemasarannya.

2. Analisis Margin Pemasaran / Fisherman's Share

Analisis margin pemasaran menggunakan rumus sebagaimana yang digunakan oleh Oktariza et al (1996), sebagai berikut:

a. Margin pemasaran

$$
\begin{aligned}
& \mathrm{MP}=\mathrm{HK}-\mathrm{HP}=\mathrm{BP}-\mathrm{KP} \\
& \text { di mana }: \quad \mathrm{MP}=\text { Margin pemasaran }
\end{aligned}
$$




$$
\begin{aligned}
\mathrm{HK}= & \text { Harga di tingkat konsumen } \\
\mathrm{HP}= & \text { Harga di tingkat nelayan } \\
\mathrm{BP}= & \text { Biaya pemasaran yang ditanggung oleh lembaga } \\
& \text { pemasaran yang terlibat } \\
\mathrm{KP}= & \text { Keuntungan yang diperoleh lembaga pemasaran } \\
& \text { yang terlibat }
\end{aligned}
$$

b. Total biaya pemasaran

$$
\begin{aligned}
& \mathrm{BP}=\mathrm{BP} 1+\mathrm{BP} 2+\mathrm{BP} 3+\ldots+\mathrm{BPk}=\mathrm{BPi} \\
& \text { di mana: } \quad \mathrm{BP}=\text { Total biaya pemasaran } \\
& \mathrm{BPi}=\text { Biaya pemasaran yang ditanggung oleh lembaga } \\
& \text { pemasaran ke-i } \\
& \mathrm{K}=1,2,3, \ldots, \mathrm{n} \text {, yaitu jumlah lembaga pemasaran yang } \\
& \text { terlibat }
\end{aligned}
$$

c. Total keuntungan pemasaran

$$
\begin{aligned}
\mathrm{KP}=\mathrm{MP}-\mathrm{BP} & \\
\text { di mana }: & \mathrm{KP}=\text { Total keuntungan pemasaran } \\
\mathrm{MP} & =\text { Margin pemasaran } \\
\mathrm{BP} & =\text { Total biaya pemasaran }
\end{aligned}
$$

d. Fisherman's share

$$
\begin{array}{ll}
\mathrm{FS}=\mathrm{HP} / \mathrm{HK} \times 100 \% \\
\text { di mana }: & \mathrm{FS}=\text { Fisherman's share } \\
\mathrm{HP}=\text { Harga di tingkat nelayan } \\
\mathrm{HK}=\text { Harga di tingkat konsumen }
\end{array}
$$

Margin pemasaran merupakan perbedaan harga di tingkat konsumen akhir dengan harga di tingkat produsen (nelayan), dan papat berarti biaya jasa-jasa pemasaran yang dibutuhkan sebagai akibat permintaan dan penawaran dari jasajasa pemasaran. Komponen margin pemasaran ini terdiri dari : (a) Biaya-biaya yang diperlukan lembaga-lembaga pemasaran untuk melakukan fungsi pemasaran, disebut biaya pemasaran, (b) keuntungan lembaga pemasaran tertentu (Sudiyono, 2002)

\section{PEMBAHASAN}

\section{Produksi, Konsumsi dan Ekspor Ikan di DIY}

Setiap jenis ikan mempunyai waktu penangkapan produktif berbeda-beda. Untuk jenis ikan tongkol banyak pada bulan Juli, maka hasil tangkapan pada musim panen ini berkisar 50 - 300 kilogram sekali melaut. Jenis layur pada bulan Oktober 
sampai Desember, kemudian jenis bawal dan lobster banyak pada bulan November. Salah satu ciri hasil perikanan adalah ketidakpastian (Soekartawi, 1989). Jenis ikan yang banyak beredar di pasaran, yaitu tenggiri, tongkol, cakalang dan kakap. Menurut laporan Kementerian Kelautan dan Perikanan (2016), kelompok ikan tuna, tongkol, dan cakalang adalah jenis ikan yang paling banyak dikonsumsi di masyarakat, yang proporsinya mencapai 16, $45 \%$ dibanding jenis ikan lainnya. Berikut adalah \% produksi ikan dari ketiga kabupaten di DIY selama tahun 2015.

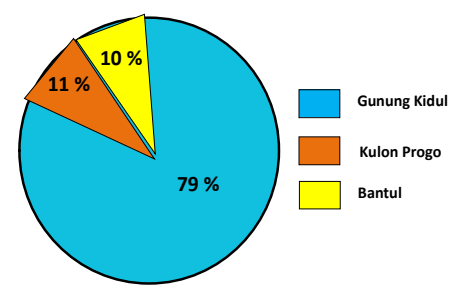

Gambar 2. Prosentase Produksi Ikan DIY Tahun 2015 Sumber: Dinas Kelautan dan Perikanan DIY, 2015, Diolah

Potensi produksi di perairan laut DIY adalah 95.000 ton per tahun. Pada tahun 2015 Badan Pusat Statistik Provinsi DIY melaporkan, dengan nelayan 5.782 orang (baik nelayan penuh dan nelayan sambilan) produksi tangkapan ikan laut terakumulasi sebanyak 3.917,60 ton. Dari total produksi tersebut, sebanyak $3.103,40$ ton $(79,22 \%)$ berasal dari wilayah Kabupaten Gunungkidul, 442,40 ton (10,78\%) dari Kabupaten Kulon Progo dan 391,80 ton (10\%) dari Kabupaten Bantul. Kabupaten Gunung Kidul masih mendominasi produksi sampai sekarang.

Produksi tangkapan ikan meliputi lebih dari 40 jenis ikan, dengan 6 jenis ikan yang banyak beredar di pasaran, sebagaimana pada tabel di bawah.

Tabel 2. Produksi dan Nilai Ikan Tangkap di Kabupaten Gunung Kidul Tahun 2015

\begin{tabular}{|l|l|r|r|r|}
\hline No & \multicolumn{1}{|c|}{ Jenis Ikan } & $\begin{array}{c}\text { Volume } \\
\text { (ton) }\end{array}$ & Harga / Kg (Rp) & \multicolumn{1}{c|}{$\begin{array}{l}\text { Nilai } \\
\text { (Rp) }\end{array}$} \\
\hline 1 & Cakalang & 1.004 & 17.000 & 17.068 .000 \\
\hline 2 & Tuna & 489 & 32.000 & 15.648 .000 \\
\hline 3 & Tongkol & 251 & 28.000 & 7.028 .000 \\
\hline 4 & Layur & 207 & 24.500 & 5.071 .500 \\
\hline 5 & Belanak & 85 & 25.000 & 2.125 .000 \\
\hline 6 & Bawal putih & 70 & 40.000 & 2.800 .000 \\
\hline \multicolumn{2}{|c|}{ Total } & 2.106 & & 49.740 .500 \\
\hline
\end{tabular}

Majalah Ilmiah Bahari Jogja 133 | http://jurnal.amy.ac.id/index.php/MIBJ/ 
Sumber: Badan Pusat Statistik Provinsi DIY (2015), Diolah

Sampling berdasarkan 6 jenis ikan diperoleh nilai sebesar $\mathrm{Rp}$ 49.740.500. Maka berdasarkan laporan Badan Pusat Statistik 2016, produksi tangkapan ikan laut DIY pada tahun 2015 untuk semua jenis ikan terakumulasi sebanyak 5.322 ton, dengan nilai sebesar Rp 125.694.996. Jumlah ini menurun sedikit dibanding hasil tahun 2014 sebanyak 5.387 ton, karena faktor cuaca. Hasil tangkapan nelayan DIY tersebut sebagian besar dijual melalui TPI (Tempat Pelelangan Ikan), dan yang terbesar melalui TPI Gunungkidul $79 \%$ atau senilai Rp 99.299.000.

Peredaran ikan di DIY tidak semuanya berasal dari kawasan perairan laut DIY, namun sebagian besar (60 \%) berasal dari luar perairan DIY terutama Pantai Utara Jawa Tengah khususnya Semarang, dan sedikit dari Jawa Timur dan Cilacap. Berikut adalah gambar prosentase ikan yang beredar di DIY.

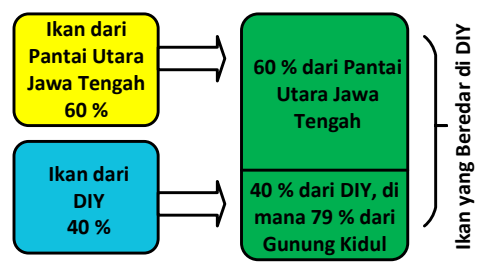

Gambar 3. Prosentase Ikan yang Beredar di DIY Sumber: Data Primer, Diolah

Produksi ikan dari DIY belum mampu mencukupi kebutuhan masyarakat DIY. Bahkan kebutuhan setiap tahun masih tergantung dari produksi luar daerah. Selain terus meningkatnya konsumsi ikan per kapita per tahun, kekurangan pasokan ikan disebabkan karena sebagian produksi (40 \%) diekspor untuk memperoleh hasil yang lebih tinggi. Komposisi ikan dari DIY tersebut (40\%) terhadap seluruh ikan adalah merupakan hasil ikan DIY setelah dikurangi ekspor $40 \%$.

Adapun volume produksi, volume ekspor dan volume konsumsi ikan masyarakat DIY dari tahun 2011 sampai 2015 adalah sebagaimana Tabel 3 di bawah. 
Tabel 3. Volume Produksi, Volume Ekspor dan Volume Konsumsi Ikan Tangkapan Nelayan DIY Tahun 2011-2015 (Ton)

\begin{tabular}{|l|c|c|c|c|c|}
\hline \multicolumn{1}{|c|}{ Keterangan } & $\mathbf{2 0 1 1}$ & $\mathbf{2 0 1 2}$ & $\mathbf{2 0 1 3}$ & $\mathbf{2 0 1 4}$ & $\mathbf{2 0 1 5}$ \\
\hline Produksi & 3.954 & 4.094 & 3.396 & 5.387 & 3.918 \\
\hline Ekspor 40 \% & 1.582 & 1.638 & 1.358 & 2.155 & 1.567 \\
\hline Konsumsi $60 \%$ & 2.372 & 2.456 & 2.038 & 3.232 & 2.351 \\
\hline
\end{tabular}

Sumber: Dinas Kelautan dan Perikanan Provinsi DIY, 2016; https://www.bps.go.id/statictable/2009/10/05/1705/produksi-perikanan-tangkapmenurut-provinsi-dan-jenis-penangkapan-2000-2015.html, Diolah $\backslash$

Pada tabel di atas nampak bahwa volume produksi sejak tahun 2011 sampai 2015 mengalami penurunan signifikan. Bahwa hasil produksi ikan DIY setiap tahun rata-rata diekspor sebesar $40 \%$, dan $60 \%$ yang dikonsumsi masyarakat DIY.

\section{Biaya Melaut}

Nelayan sebagai “produsen” ikan laut setiap kali melaut mengeluarkan biayabiaya sekaligus menerima hasil penjualan ikan. Analisis selengkapnya dapat dilihat pada Tabel 4 berikut.

Tabel 4. Biaya Melaut dengan Kapal Motor Tempel

\begin{tabular}{|l|c|l|}
\hline \multicolumn{1}{|c|}{ Uraian Biaya } & $\begin{array}{c}\text { Nilai } \\
\text { (Juta Rupiah) }\end{array}$ & \% \\
\hline Biaya buruh & 1,70 & 40,94 \\
\hline Bahan bakar & 0,90 & 21,21 \\
\hline Oli & 0,10 & 1,73 \\
\hline Garam dan es balok & 0,20 & 4,37 \\
\hline Perbekalan & 0,70 & 15,99 \\
\hline Sewa alat & 0,20 & 5,16 \\
\hline Pemeliharaan sarana & 0,10 & 3,40 \\
\hline Penyusutan kapal & & \\
\hline Biaya lainnya & 0,20 & 3,66 \\
\hline Total & 0,10 & 3,53 \\
\hline Sumber: Data Prima & $\mathbf{4 , 1 0}$ & $\mathbf{1 0 0}$ \\
\hline
\end{tabular}

Sumber: Data Primer, Diolah

Biaya produksi yang dikeluarkan untuk sekali melaut meliputi meliputi 3 (tiga) kategori, yaitu biaya buruh, biaya bahan, dan biaya lainnya. Masing-masing kategori biaya adalah: (a) Biaya buruh, baik buruh dibayar maupun perkiraan buruh 
tidak dibayar/pekerja keluarga; (b) Biaya bahan terdiri dari bahan bakar minyak (bensin, solar), oli, garam dan es balok, perbekalan baik yang berasal dari pembelian maupun perkiraan nilai dari bukan pembelian; (c) Biaya lainnya, yaitu sewa alat, penyusutan barang modal, dan lainnya (retribusi jasa perikanan, wadah, dan sebagainya).

Berdasarkan Peraturan Daerah Kabupaten Gunungkidul Nomor 8 Tahun 2012 tentang Retribusi Tempat Pelelangan, retribusi yang dikenakan terhadap kegiatan perikanan laut adalah sebesar $5 \%$ dari harga transaksi yang dibebankan kepada pihak penjual dan pembeli dengan perincian sebagai berikut: (a) pihak penjual atau nelayan sebesar $3 \%$ dan pihak pembeli sebesar $2 \%$. Dari ketiga kategori biaya tersebut proporsi terbesar adalah biaya buruh yang mencapai 40,94\% kemudian biaya bahan terutama biaya bahan bakar minyak (BBM) sebesar 21,21\%.

Adapun hasil tangkapan rata-rata pada musim normal, tidak sedang musim panen atau musim paceklik ikan sebesar Rp 6,20 juta, sehingga hasil bersih nelayan adalah Rp 6,20 juta $-\mathrm{Rp} \mathrm{4,10} \mathrm{juta}=\mathrm{Rp} 2,10$ juta. Jika rata-rata setiap kapal motor tempel diawaki 3 orang maka hasil bersih setiap nelayan adalah $\mathrm{Rp} 0,70$ juta sekali melaut. Hasil ini merupakan pola pemasaran nelayan -TPI, karena mayoritas nelayan menjual hasil tangkapannya melaui TPI. Data volume ikan DIY yang dijual melalui TPI pada tahun 2014 sebesar 2. 769,60 ton dan pada tahun 2015 turun menjadi 2.339, 50 ton (Badan Pusat Statistik DIY, 2016).

\section{Saluran Pemasaran}

Hasil penelitian ini menemukan saluran pemasaran ikan di DIY sebagai berikut.

\section{Peran Tempat Pelelangan Ikan (TPI)}

Pemerintah Kabupaten Gunung Kidul adalah sebagai fasilitator penyediaan TPI, maka semua transaksi ikan wajib melalui TPI untuk dapat dikutip retribusinya sebesar $5 \%$. Cara kerja TPI adalah dengan menimbang hasil tangkapan nelayan, kemudaian memilah-milah sesuai jenis ikan, dan menginformasikan harga masingmasing jenis ikan. Penentuan harga dengan cara pedagang pengumpul bersama petugas TPI yang netral (dibentuk oleh Pemda Gunung Kidul) memutuskan harga 
tertentu. Jika nelayan masih keberatan atas keputusan harga tersebut maka petugas TPI bernegosiasi dengan pedagang pengumpul sampai diperoleh harga yang cocok. Penentu harga sejatinya adalah pedagang pengumpul yang diformalkan lembaga TPI.

\section{Saluran Pemasaran 1 (SP 1)}

SP 1 adalah saluran pemasaran paling pendek, yaitu Nelayan - TPI Konsumen akhir. Cara pengutipan retribusi ini adalah harga yang ditentukan TPI + $5 \%$, di mana nelayan menanggung $3 \%$ dan wisatawan $2 \%$ dari. Model SP 1 ini terjadi ketika nelayan yang baru mendaratkan kapalnya dan hasilnya langsung dibeli oleh konsumen akhir, yaitu para pengunjung pantai / wisatawan dengan "menjemput" nelayan.

SP 1 terjadi ketika hasil tangkapan nelayan tidak banyak. Pada hai-hari biasa volume ikan yang dapat terjual rata-rata 40 kilogram per hari per nelayan, namun jika pada hari-hari liburan dapat meningkat sampai 50 kilogram per hari per nelayan. Adapaun besar margin pemasaran adalah sebesar Rp 3.000 per kilogram untuk rata-rata semua jenis ikan.

Pada SP 1 tidak ada biaya pemasaran, yang ada adalah biaya produksi berupa biaya melaut, maka margin pemasaran adalah sebesar biaya retribusi $5 \%$ per kilogram untuk semua jenis ikan, atau harga yang dibayarkan oleh wisatawan $=$ harga pokok ikan + biaya retribusi $5 \%$, di mana yang $3 \%$ akan diteruskan dibayarkan oleh nelayan ke TPI. Saluran pemasaran ini paling efektif dan paling adil (Mubyarto, 1989), karena tanpa melibatkan pedagang perantara. Fisher man's share SP 1 sebagaimana Tabel 5 berikut.

Tabel 5. Fisherman's Share pada SP 1

\begin{tabular}{|c|l|c|c|c|c|c|c|}
\hline No & Jenis Ikan & $\begin{array}{c}\text { Harga } \\
\text { jual } \\
\text { nelayan } \\
/ \mathrm{Kg} \\
(\mathrm{Rp})\end{array}$ & $\begin{array}{c}\text { Retribusi } \\
3 \% \\
\text { ditanggung } \\
\text { nelayan } \\
(\mathrm{Rp})\end{array}$ & $\begin{array}{c}\text { Retribusi } \\
2 \% \\
\text { ditanggung } \\
\text { konsumen } \\
\text { akhir (Rp) }\end{array}$ & $\begin{array}{c}\text { Harga beli } \\
\text { Konsumen } \\
\text { akhir } \\
/ \mathrm{kg}(\mathrm{Rp})\end{array}$ & $\begin{array}{c}\text { Margin } \\
\text { pemasaran } \\
/ \mathrm{kg}(\mathrm{Rp})\end{array}$ & $\begin{array}{c}\text { Fisherman's } \\
\text { share } \\
(\%)\end{array}$ \\
\hline$(1)$ & \multicolumn{1}{|c|}{$(2)$} & $(3)$ & $(4)$ & $(5)$ & $(6)$ & $(7)$ & $(8)$ \\
\hline 1 & Cakalang & 17.000 & 510 & 340 & 17.850 & 850 & 95 \\
\hline 2 & Tuna & 32.000 & 960 & 640 & 33.600 & 1.600 & 95 \\
\hline 3 & Tongkol & 28.000 & 840 & 560 & 29.400 & 1.400 & 95 \\
\hline 4 & Layur & 24.500 & 735 & 490 & 25.725 & 1.225 & 95 \\
\hline 5 & Belanak & 25.000 & 750 & 500 & 26.250 & 1.250 & 95 \\
\hline
\end{tabular}




\begin{tabular}{|l|l|l|r|r|r|r|r|}
\hline 6 & $\begin{array}{l}\text { Bawal } \\
\text { putih }\end{array}$ & 40.000 & 1.200 & 800 & 42.000 & 2.000 & 95 \\
\hline 7 & Pari & 11.000 & 330 & 220 & 11.550 & 550 & 95 \\
\hline 8 & Tenggiri & 25.000 & 750 & 500 & 26.250 & 1.250 & 95 \\
\hline
\end{tabular}

Sumber: Data Primer, Diolah

Jenis ikan yang dipasarkan pada SP 1 ini bervariasi dari jenis dengan harga ekonomis, misalnya ikan pari dan cakalang, ikan yang nilai ekonominya lebih tinggi misalnya ikan tuna, serta ikan kelas mahal misalnya bawal putih.

Besarnya retribusi $5 \%$ dibebankan kepada wisatawan, namun sebetulnya yang $3 \%$ harus disetorkan ke TPI, sehingga sebetulnya keuntungan nelayan sebesar $2 \%$ dari harga jual nelayan. Contoh ikan cakalang keuntungan adalah Rp 340 per kilogram dan seterusnya, sehingga kolom (5) pada tabel di atas merupakan keuntungan bagi nelayan untuk tiap kilogram yang dijual.

Margin pemasaran tiap jenis ikan bervariasi, namun fisherman's share untuk semua jenis ikan adalah $95 \%$, artinya $95 \%$ harga jual ikan diterima nelayan, sedangkan yang $5 \%$ diterima TPI sebagai koordinator.

\section{Saluran Pemasaran 2 (SP 2)}

SP 2 adalah saluran pemasaran dari Nelayan - TPI - Pedagang Pengumpul Pedagang Pengecer - Konsumen Akhir. Aliran ikan dari nelayan ke pedagang pengecer melaui pedagang pengumpul dimediasi oleh TPI. Seterusnya dari pedagang pengecer ke konsumen akhir menjadi tanggungjawab pedagang pengecer.

Nelayan menjual ikan hasil tangkapan ke pedagang pengecer melalui pedagang pengumpul (lihat Hanafiah dan Saefudin, 2010). Berdasarkan inventarisasi lapangan jumlah pedagang pengumpul sebanyak 7 orang, mereka sebagai "pembentuk" harga TPI. Pedagang pengumpul mempunyai kemampuan penyediaan modal lebih dulu dalam biaya penangkapan ikan yang harus ditanggung nelayan. Maka di antara nelayan ada beberapa yang menggunakan "fasilitas ijon" oleh pedagang pengumpul, nelayan dalam melaut biayanya dipinjami lebih dulu oleh pedagang pengumpul, setelah memperoleh hasil harus dijual kepada pedagang pengumpul tersebut.

Volume distribusi ikan sebagaian besar (90\%) melalui pedagang pengumpul, yang langsung nelayan-konsumen akhir hanya $10 \%$. Maka share volume ikan yang 
akan diteruskan kepada pelaku pasar berikutnya tergantung perolehan hasil yang dibeli dari nelayan oleh masing-masing anggota pedagang pengumpul. Salah satunya adalah hasil dari praktek "ijon”.

Jumlah pedagang pengecer sebanyak 35 orang, sebagian merupakan keluarga nelayan. Tempat menjual pedagang eceran ada 3, yaitu di pantai tersebut, di pasarpasar tradidional, dan pedagang pengecer yang mengedarkan dagangannya dengan motor dari desa- ke desa. Jenis ikan yang diedarkan melalui SP 2 ini pada umumnya yang bernilai murah sehingga terjangkau oleh masyarakat di pasar-pasar tradisional, misalnya cakalang dan tongkol. Jenis ikan bawal putih dan lobster yang bernilai ekonomi tinggi dijual melalui saluran pemasaran lain.

Biaya retribusi $5 \%$ yang pada awalnya ditanggung oleh pedagang pengumpul yang kemudian secara berantai diteruskan ke pedagang pengecer dan terakhir ke konsumen akhir. Pada akhirnya sebesar $3 \%$ dibayarkan nelayan ke TPI, sisanya yang $2 \%$ dibayarkan pedagang pengumpul ke TPI juga sebagai beban konsumen akhir, walaupun asalnya $5 \%$ tersebut semua dari konsumen akhir.

Keuntungan pedagang pengumpul pada kolom (6) dan keuntungan pada pedagang pengecer (kolom 9). Biaya pemasaran pada pedagang pengumpul berupa penyediaan wadah, sewa tempat untuk mengepul ikan, es balok, dan buruh. Sedangkan biaya pemasaran bagi pedagang pengecer berupa wadah, es balok, alat transportasi motor, dan tenaga untuk mengecerkannya. Harga jual pada pedagang pengecer pada kolom (9) adalah harga akhir yang dibayarkan konsumen akhir. Konsumen akhir terdiri dari wisatawan, konsumen di pasar-pasar tradisional, dan konsumen dari kampung-kampung yang membeli dari pedagang eceran keliling. Tabel 6 berikut adalah fisher man's share pada SP 2. 
Tabel 6. Fisherman's Share pada SP 2

\begin{tabular}{|c|c|c|c|c|c|c|c|c|c|c|c|}
\hline $\begin{array}{c}\mathrm{N} \\
\mathrm{o}\end{array}$ & $\begin{array}{c}\text { Jenis } \\
\text { Ikan }\end{array}$ & $\begin{array}{c}\text { Harga } \\
\text { jual } \\
\text { nelayan } \\
\text { / kg } \\
\text { (Rp) }\end{array}$ & $\begin{array}{l}\text { Retr. } 5 \% \\
\text { ditanggun } \\
\text { g pedag. } \\
\text { pengum. } \\
\text { /kg (Rp) }\end{array}$ & $\begin{array}{l}\text { Biaya } \\
\text { pemas. } \\
\text { pedag. } \\
\text { pengum. } \\
\text { / kg } \\
\text { (Rp) }\end{array}$ & \begin{tabular}{|c|}
$\begin{array}{c}\text { Keunt. } \\
\text { pedag. } \\
\text { pengum }\end{array}$ \\
$\cdot \dot{\mathrm{kg}}$ \\
$(\mathrm{Rp})$
\end{tabular} & $\begin{array}{l}\text { Harga } \\
\text { jual } \\
\text { pedag. } \\
\text { pengum. } \\
\text { / kg (Rp) }\end{array}$ & $\begin{array}{c}\text { Biaya } \\
\text { pemas. } \\
\text { pedag. } \\
\text { pengece } \\
\text { r } \\
/ \mathrm{kg} \\
(\mathrm{Rp})\end{array}$ & $\begin{array}{c}\text { Keunt. } \\
\text { pedag. } \\
\text { pengece } \\
\text { r } \\
\text { / kg (Rp }\end{array}$ & $\begin{array}{l}\text { Harga } \\
\text { jual } \\
\text { pedag. } \\
\text { pengecer } \\
\text { /kg (Rp) }\end{array}$ & $\begin{array}{l}\text { Margin } \\
\text { pemas. } \\
\text { /kg } \\
(\mathrm{Rp})\end{array}$ & $\begin{array}{c}\text { Fisher } \\
\text { man's } \\
\text { share } \\
(\%)\end{array}$ \\
\hline (1) & (2) & (3) & (4) & (5) & (6) & (7) & $(8)$ & (9) & (10) & (11) & (12) \\
\hline 1 & Cakalang & 17.000 & 850 & 2.000 & 4.150 & 24.000 & 3.000 & 3.000 & 30.000 & 13.000 & 57 \\
\hline 2 & Tuna & 32.000 & 1.600 & 2.000 & 3.900 & 39.500 & 3.000 & 2.500 & 45.000 & 13.000 & 71 \\
\hline 3 & Tongkol & 28.000 & 1.400 & 2.000 & 4.100 & 35.500 & 3.000 & 1.000 & 39.500 & 11.500 & 71 \\
\hline 4 & Layur & 24.500 & 1.225 & 2.000 & 4.250 & 32.000 & 3.000 & 2.000 & 37.000 & 12.500 & 66 \\
\hline 5 & Belanak & 25.000 & 1.250 & 2.000 & 4.750 & 33.000 & 3.000 & 2.000 & 38.000 & 13.000 & 66 \\
\hline 6 & Pari & 11.000 & 550 & 2.000 & 3.450 & 17.000 & 3.000 & 3.000 & 23.000 & 12.000 & 48 \\
\hline 7 & Tenggiri & 25.000 & 1.250 & 2.000 & 4.750 & 33.000 & 3.000 & 2.000 & 38.000 & 13.000 & 66 \\
\hline
\end{tabular}

Sumber: Data Primer, Diolah

Keterangan:

Retr = Retribusi

pemas. pedag. Pengum $=$ Pemasaran pedagang pengumpul

Keunt. pedag. Pengum = Keuntungan pedagang pengumpul

pemas. pedag. Pengecer $=$ Pemasaran pedagang pengecer

Margin pemas. $\quad=$ Margin pemasaran 


\section{Saluran pemasaran 3 (SP 3)}

Saluran pemasaran ini adalah adanya pelaku rumah makan dalam distribusi ikan. Bahwa di tempat-tempat wisata adanya rumah makan adalah hal yang wajar sebagai bagian dari komponen wisata. Pantai-pantai di DIY adalah tempat destinasi wisata yang sekaligus ada kegiatan penangkapan ikan dan ada TPI-nya. Rumah makan tersebut menjual ikan olahan kepada pengunjung / wisatawan dalam bentuk olahan. Bentuk SP 3 adalah Nelayan - TPI - Pedagang Pengumpul - Rumah Makan - Konsumen Akhir.

Pada SP 3 pedagang pengumpul menjual ikan ke rumah makan - rumah makan yang ada di pantai tersebut, dan seterusnya ke konsumen akhir. Jenis ikan yang dijual pada SP 3 ini lebih bernilai daripada jenis ikan pada SP 2. Berikut adalah tabel fisher man's share pada SP 3.

Biaya retribusi $5 \%$ yang pada awalnya ditanggung oleh pedagang pengumpul yang kemudian secara berantai diteruskan ke rumah makan dan terakhir ke pembeli ikan olahan sebagai konsumen akhir di rumah makan. Pada akhirnya kutipan retribusi sebesar $3 \%$ dibayarkan nelayan ke TPI, sisanya yang $2 \%$ dibayarkan pedagang pengumpul ke TPI juga sebagai beban pembeli ikan olahan di rumah makan. Sebagaimana pada SP 2 semua biaya retribusi $5 \%$ berasal dari pembeli di warung makan, agar memenuhi Peraturan Daerah Kabupaten Gunungkidul Nomor 8 Tahun 2012.

Tabel 7 menunjukkan fisherman's Share pada SP 3. Keuntungan pedagang pengumpul pada kolom (6) ternyata kalah dengan keuntungan rumah makan pada pada kolom (9). Argumentasi bahwa ikan yang dimasak harus ditambah biaya memasak dan biaya penyajian. Akibatnya harga jual dan keuntungan pada rumah makan lebih tinggi daripada pedagang pengumpul apalagi pedagang pengecer.

Rumah makan sebagai bagian dari saluran pemasaran ikan juga mempunyai kekuatan modal tinggi. Maka wajar jika keuntungannya juga tinggi. Biaya pemasaran pada rumah makan berupa sewa tempat untuk usaha warung makan, penyediaan wadah, es balok, buruh, promosi. Sedangkan biaya pemasaran bagi pedagang pengecer berupa wadah, es balok, alat transportasi motor, dan tenaga untuk mengecerkannya.

Majalah Ilmiah Bahari Jogja 141 | http://jurnal.amy.ac.id/index.php/MIBJ/ 
Tabel 7. Fisherman's Share pada SP 3

\begin{tabular}{|c|c|c|c|c|c|c|c|c|c|c|c|}
\hline No & $\begin{array}{l}\text { Jenis } \\
\text { Ikan }\end{array}$ & $\begin{array}{c}\text { Harga } \\
\text { jual } \\
\text { nelayan } \\
\text { / kg } \\
\text { (Rp) }\end{array}$ & $\begin{array}{l}\text { Retr. } 5 \% \\
\text { ditanggung } \\
\text { pedag. } \\
\text { pengum. } \\
\text { /kg (Rp) }\end{array}$ & $\begin{array}{c}\text { Biaya } \\
\text { pemas. } \\
\text { pedag. } \\
\text { pengum. } \\
\text { / kg (Rp) }\end{array}$ & $\begin{array}{l}\text { Keunt. } \\
\text { pedag. } \\
\text { pengum } \\
\text {. } \\
/ \mathrm{kg} \\
(\mathrm{Rp})\end{array}$ & $\begin{array}{c}\text { Harga } \\
\text { jual } \\
\text { pedag. } \\
\text { pengum. } \\
\text { / kg (Rp) }\end{array}$ & $\begin{array}{l}\text { Biaya } \\
\text { pemas. } \\
\text { rumah } \\
\text { makan } \\
\text { / kg }(\mathrm{Rp})\end{array}$ & $\begin{array}{l}\text { Keunt. } \\
\text { rumah } \\
\text { makan } \\
\text { / kg }(\mathrm{Rp})\end{array}$ & $\begin{array}{c}\text { Harga } \\
\text { jual } \\
\text { rumah } \\
\text { makan } \\
\text { /kg }(\mathrm{Rp})\end{array}$ & $\begin{array}{l}\text { Margin } \\
\text { pemas. } \\
\text { /kg } \\
(\mathrm{Rp})\end{array}$ & $\begin{array}{c}\text { Fisher } \\
\text { man's } \\
\text { share } \\
(\%)\end{array}$ \\
\hline (1) & (2) & (3) & (4) & (5) & (6) & (7) & (8) & (9) & (10) & (11) & (12) \\
\hline 1 & $\begin{array}{l}\text { Cakalan } \\
\mathrm{g}\end{array}$ & 17.000 & 850 & 2.000 & 6.150 & 26.000 & 1.500 & 7.500 & 35.000 & 18.000 & 49 \\
\hline 2 & Tuna & 32.000 & 1.600 & 2.000 & 3.900 & 39.500 & 1.500 & 9.000 & 50.000 & 18.000 & 64 \\
\hline 3 & Tongkol & 28.000 & 1.400 & 2.000 & 4.100 & 35.500 & 1.500 & 8.000 & 45.000 & 17.000 & 62 \\
\hline 4 & Layur & 24.500 & 1.225 & 2.000 & 4.250 & 32.000 & 1.500 & 8.500 & 42.000 & 17.500 & 58 \\
\hline 5 & Belanak & 25.000 & 1.250 & 2.000 & 4.750 & 33.000 & 1.500 & 8.500 & 43.000 & 18.000 & 58 \\
\hline 6 & Pari & 11.000 & 550 & 2.000 & 3.450 & 17.000 & 1.500 & 9.500 & 28.000 & 17.000 & 39 \\
\hline 7 & Tenggiri & 25.000 & 1.250 & 2.000 & 4.750 & 33.000 & 1.500 & 8.500 & 43.000 & 18.000 & 58 \\
\hline
\end{tabular}

Sumber: Data Primer, Diolah

Keterangan:

Retr.

$=$ Retribusi

pemas. pedag. pengum.

= Pemasaran pedagang pengumpul

Keunt. pedag. pengum. = Keuntungan pedagang pengumpul

Margin pemas.

$=$ Margin pemasaran 
Harga jual pada rumah makan pada kolom (10) adalah harga akhir yang dibayarkan pembeli ikan olahan rumah makan tersebut sebagai konsumen akhir. Konsumen akhir adalah wisatawan pantai. Jika dibandingkan dengan SP 2, fisher man's share pada SP 3 secara umum lebih kecil untuk semua jenis ikan. Artinya bagian harga jual yang dinikmati nelayan terhadap harga akhir semakin kecil pada SP 3. Atau, keuntungan pada rumah makan lebih besar daripada keuntungan pada pedagang pengumpul.

\section{Saluran Pemasaran 4 (SP 4)}

Saluran pemasaran 4 dibentuk oleh pelaku Nelayan - TPI - Pedagang Pengumpul - Industri Pengolah. Sebagaimana pada SP 3 aliran ikan dari nelayan ke pedagang pengumpul dikoordinir oleh TPI. Seterusnya oleh pedagang pengumpul diteruskan ke industri pengolah ikan yang ada di kota-kota besar di luar DIY. Untuk memperoleh ikan dari beberapa TPI diwakili oleh pedagang besar atau agen. Pola SP 4 ini meminta ikan jenis dan kualitas yang standar. Persyaratan standar yang diminta industri pengolahan ikan mengacu pada Hardiana (2009), sebagaimana Tabel 8 berikut.

Tabel 8. Persyaratan Standar Ikan untuk Industri

\begin{tabular}{|l|l|}
\hline Karakteristik & \multicolumn{1}{|c|}{ Keadaan } \\
\hline Mata & Bersih, terang, menonjol \\
\hline Kulit & Bersih, cerah \\
\hline Bau & Segar \\
\hline Tekstur daging & $\begin{array}{l}\text { Keras, kenyal, elastis, jaringan } \\
\text { tidak pecah }\end{array}$ \\
\hline Warna daging & $\begin{array}{l}\text { Merah tua seperti bunga } \\
\text { mawar, atau seperti buah } \\
\text { semangka }\end{array}$ \\
\hline Kondisi ikan & Penampakan bagus, utuh \\
\hline
\end{tabular}

Sumber: Hardiana (2009) dan Data Primer, Diolah

Jenis ikan yang diminta oleh industri pengolah misalnya tengiri, bawal putih, dan tongkol yang mempunyai nilai ekonomi tinggi, sekaligus dengan standar yang ketat baik mutu maupun ukuran beratnya. Pola ini tidak dapat kontinyu mengingat hasil tangkapan yang tidak menentu. Maka industri pengolahan ini selalu mencari di TPI-TPI di lain tempat untuk menjaga kontinyuitas produksinya. 
Peran pedagang pengumpul dalam mensortir ikan lebih ketat untuk melayani permintaan kualitas standar yang ditentukan pabrik. Industri pengolah selain berfungsi sebagai pelaku saluran distribusi juga sebagai penentu harga. Karena hasil industri pengolah ini adalah terutama untuk tujuan pasar ekspor maka harga jual tidak diperoleh informasi, maka margin pemasaran atau fisher man's share juga tidak dapat diperoleh. Namun diperkirakan harga jual dapat mencapai 3 kali atau bahkan lebih dari harga beli pada pedagang pengumpul (Wawancara dengan pedagang pengumpul), namun validitasnya tidak meyakinkan.

Fisherman's share pada SP 4 dapat diketahui pada Tabel 9 di bawah ini.

Tabel 9. Fisherman's Share pada SP 4

\begin{tabular}{|l|l|r|l|r|r|r|r|c|}
\hline No & $\begin{array}{c}\text { Jenis } \\
\text { Ikan }\end{array}$ & $\begin{array}{c}\text { Harga } \\
\text { jual } \\
\text { nelayan } \\
/ \mathrm{kg} \\
(\mathrm{Rp})\end{array}$ & $\begin{array}{l}\text { Retr. 5\% } \\
\text { ditanggung } \\
\text { pedag. } \\
\text { pengum. } \\
/ \mathrm{kg}(\mathrm{Rp})\end{array}$ & $\begin{array}{c}\text { Biaya } \\
\text { pemas. } \\
\text { pedag. } \\
\text { pengum. } \\
/ \mathrm{kg} \\
(\mathrm{Rp})\end{array}$ & $\begin{array}{c}\text { Keunt. } \\
\text { pedag. } \\
\text { pengum. } \\
/ \mathrm{kg}(\mathrm{Rp})\end{array}$ & $\begin{array}{c}\text { Harga } \\
\text { jual } \\
\text { pedag. } \\
\text { pengum. } \\
/ \mathrm{kg} \\
(\mathrm{Rp})\end{array}$ & $\begin{array}{c}\text { Margin } \\
\text { pemas. } \\
/ \mathrm{kg} \\
(\mathrm{Rp})\end{array}$ & $\begin{array}{c}\text { Fisher } \\
\text { man's } \\
\text { share } \\
(\%)\end{array}$ \\
\hline$(1)$ & $(2)$ & $(3)$ & $(4)$ & $(5)$ & $(6)$ & $(7)$ & & $(12)$ \\
\hline 1 & Cakalang & 17.000 & 850 & 2.000 & 8.150 & 28.000 & 11.000 & 61 \\
\hline 2 & Tuna & 32.000 & 1.600 & 2.000 & 9.400 & 45.000 & 23.000 & 71 \\
\hline 3 & Tongkol & 28.000 & 1.400 & 2.000 & 6.600 & 38.000 & 10.000 & 74 \\
\hline 4 & Layur & 24.500 & 1.225 & 2.000 & 7.275 & 35.000 & 9.500 & 70 \\
\hline 5 & Belanak & 25.000 & 1.250 & 2.000 & 6.750 & 35.000 & 10.000 & 71 \\
\hline 6 & Lobster & 275.000 & 13.750 & 2.000 & 34.250 & 325.000 & 50.000 & 85 \\
\hline 7 & Tenggiri & 25.000 & 1.250 & 2.000 & 6.750 & 35.000 & 10.000 & 71 \\
\hline
\end{tabular}

Sumber: Data Primer, Diolah

Keterangan:

Retr. = Retribusi

pemas. pedag. pengum. = Pemasaran pedagang pengumpul

Keunt. pedag. pengum. = Keuntungan pedagang pengumpul

Margin pemas. $\quad=$ Margin pemasaran

Jenis ikan yang dipasarkan melalui SP 4 ini adalah yang bernila tinggi, misalnya lobster. Harga jual di tingkat pedagang pengumpul paling tinggi adalah untuk melayani industri pengolah daripada untuk rumah makan apalagi untuk pedagang pengecer. Akibatnya margin pemasaran juga meningkat. Sampai pada tingkat saluran pedagang pengumpul fisherman's share masih tinggi (di atas $60 \%$ untuk semua jenis ikan). Namun pedagang pengumpul bukan konsumen akhir. Melalui industri pengolah, ikan kemudian dipasarkan ke konsumen akhir di pusat- 
pusat pembelanjaan di luar negeri, yang ini tidak mungkin terlacak. Jika produk sampai konsumen akhir diperkirakan fisherman's share tinggal $20 \%$ atau bahkan kurang. Artinya bagian harga yang diterima nelayan semakin kecil di antara saluran pemasaran sbelumnya (SP1, SP2, SP3). Hal ini menurut Hanafiah dan Saefudin (2010) dan Mubyarto (1989), merupakan saluran pemasaran paling tidak efektif dan paling tidak adil.

\section{PENUTUP}

\section{Kesimpulan}

1. Hasil produksi ikan DIY $60 \%$ diedarkan di DIY dan $40 \%$ diekspor terutama jenis ikan yang bernilai tinggi. Peredaran ikan laut di DIY $40 \%$ berasal dari DIY dan $60 \%$ dari Pantai Utara Jawa Tengah.

2. Ada 4 (empat) saluran pemasaran ikan laut di DIY. Saluran Pemasaran 1 adalah nelayan- TPI - konsumen akhir dengan fisherman's share $95 \%$ untuk semua jenis ikan, saluran pemasaran ini paling efektif dan paling adil. Saluran Pemasaran 2 adalah nelayan - TPI pedagang pengumpul pedagang pengecer - konsumen akhir dengan fisherman's share bervariasi antara $48 \%$ sampai $71 \%$. Saluran Pemasaran 3 adalah nelayan - TPI pedagang pengumpul - rumah makan - konsumen akhir, dengan fisherman's share bervariasi antara $39 \%$ sampai 64 \%. Saluran Pemasaran 4 adalah nelayan - TPI - pedagang pengumpul - industri pengolah konsumen akhir. Pada saluran pemasaran 4 fisherman's share diketahui hanya sampai pada pedagang pengumpul, karena keterbatasan harga jual pada industri pengolah. Hasil fisherman's share bervariasi dari $61 \%$ sampai $85 \%$, dan SP 4 merupakan saluran pemasaran yang paling tidak efektif.

3. Transaksi penjualan pada semua saluran pemasaran selalu melibatkan TPI sebagai mediator antara nelayan dengan pelaku pemasaran berikutnya.

\section{Saran}

Memperpendek saluran pemasaran agar fisherman's share dapat meningkat yang berarti peningkatan kesejahteraan nelayan dan sekaligus harga yang sampai

Majalah Ilmiah Bahari Jogja 145 | http://jurnal.amy.ac.id/index.php/MIBJ/ 
ke konsumen akhir lebih murah, caranya nelayan menjalin kerjasama langsung dengan konsumen akhir.

\section{DAFTAR PUSTAKA}

Adisasmita, R. (2006). Pembangunan Kelautan dan Kewilayahan. Graha Ilmu, Yogyakarta.

Badan Pusat Statistik DIY, 2015.

Balitbang Kementerian Pertahanan, 2012.

Bourlakis, M., and Weightman, P. (2004). Introduction to the UK food supply chain. In Food Supply Chain Management. Bourlakis, M., and Weightman, P. (Eds), pp. 1-10.

Dinas Kelautan dan Perikanan Provinsi DIY, 2015.

Dinas Kelautan dan Perikanan Provinsi DIY, 2016.

Hanafiah, A.M., dan Saefuddin, A.M. (2010). Tata Niaga Hasil Perikanan. UI Press, Jakarta.

Hanafie, R. (2010). Pengantar Ekonomi Pertanian. CV. Andi Offset, Yogyakarta.

Hardiana, P.K. (2009). Evaluasi Risiko Semi-Quantitatie Kadar Histamin Ikan Tuna pada Proses Pembongkaran di Transit dan Pengolahan Produk Tuna Loin Beku. Skripsi. Institut Pertanian Bogor.

Kamiso, H.N. (2002). Laporan Akhir Pemetaan Sumber Daya Kelautan dan Survey Sosial Ekonomi Nelayan. Dinas Kelautan dan Perikanan Provinsi DIY dan Jurusan Perikanan Fakultas Pertanian UGM, Yogyakarta.

Kedaulatan Rakyat, 4 Februari 2016.

Kementerian Kelautan dan Perikanan, 2016.

Kotler, P, and Keller, K.L. (2012). Marketing Management 14e Global Edition, Pearson, Boston.

Laporan Kinerja Kementerian Kelautan dan Perikanan Tahun 2014.

McCarthy, E.J., and Perreault, W.D. (2002). Basic Marketing: A GlobalManagerial Approach, 14 th ed. McGraw-Hill, Homewood, IL.

Mubyarto. (1989). Pengantar Ekonomi Pertanian. LP3ES, Jakarta.

Majalah Ilmiah Bahari Jogja 146 | http://jurnal.amy.ac.id/index.php/MIBJ/ 
Oktariza, W., Fahrudin, A., Istiqlaliyah, M., Yatri I. Kusumastnti, Y.I., dan Antoni, H. (1996). Studi Distribusi Pemasaran Hasil Perikanan Lautdari Pelabuhan Ratu, Sukabumi, Jawa Barat. Buletin Ekonomi Periklman. No.2 Tahun ke 2, pp. 34-41.

Pembangunan Kelautan dan Perikanan dalam Prioritas Pembangunan Nasional 2015-2019. (2013). Bappenas.

Soekartawai. (1989). Prinsip Dasar Ekonomi Pertanian - Teori dan Aplikasi. CV. Rajawali, Jakarta.

Soekartawai. (1993). Prinsip Dasar Manajemen Pemasaran Hasil- Hasil Pertanian - Teori dan Aplikasinya. PT. RajaGrafindo Persada, Jakarta.

Soekartawai. (1995). Analisis Usaha Tani. UI Press, Jakarta.

Statistik Sumberdaya Laut dan Pesisir 2016. Badan Pusat Statistik, Jakarta.

Sudiyono. (2002). Pemasaran Pertanian. UMM Press, Malang.

Sugiyono. (2014). Statistika untuk Penelitian. Alfabeta, Bandung.

Watanabe, K., Schuster, E, W. (2003). The Impact of e-Commerce on the Japanese Raw Fish Supply Chain.

Webster, F.E. Jr. (1992). The changing role of marketing in the corporation. Journal of Marketing. Vol. 56 No. 4, October 1992, pp. 1-17.

Peraturan Daerah Kabupaten Gunungkidul Nomor 8 Tahun 2012 tentang Retribusi Tempat Pelelangan.

https://www.bps.go.id/statictable/2009/10/05/1705/produksi-perikanan-tangkapmenurut-provinsi-dan-jenis-penangkapan-2000-2015.html, diunduh 20 Maret 2016. 